\title{
Desigualdades socioespaciais e escolhas escolares
}

\author{
Gustavo Bruno De Paula* \\ Universidade Federal de Minas Gerais \\ Maria Alice de Lima Gomes Nogueira ** \\ Universidade Federal de Minas Gerais
}

Resumo Este artigo apresenta resultados de uma pesquisa cuja temática se inscreve na interseção das problemáticas clássicas da sociologia da educação e da sociologia urbana. Objetivando compreender se e de que maneira as desigualdades socioespaciais impactam as desigualdades escolares, analisamos o modo como determinadas características sociais e urbanas de um território estruturam as estratégias e as escolhas escolares das famílias ali residentes. Para tanto, examinamos duas sub-regiões da região do Barreiro, situada em Belo Horizonte, as quais apresentam contrastes socioeconômicos e urbanos. Partindo da noção de "geografia de oportunidades", comparamos as estratégias e escolhas escolares efetuadas pelas famílias que vivem nessas duas áreas, procurando identificar de que maneira as características sociais do entorno constrangem ou favorecem suas preferências escolares. Os resultados indicaram um efeito da distribuição desigual das oportunidades escolares sobre as escolhas parentais, derivado das características quantitativas e qualitativas da oferta escolar local.

PALAVRAS-CHAVE: Desigualdades socioespaciais; Desigualdades escolares; Escolha do estabelecimento de ensino. 


\section{Sociospatial inequalities and school choice}

Abstract These article shows the results of a research, whose problem is in the intersection of classical problems of sociology of education and urban sociology. Aiming to understand if and how socio-spatial inequalities impact on schooling inequalities, we analyzed the way certain social and urban characteristics of a territory structure the strategies and families' school choices. In order to do so, we examined two sub-regions in the Barreiro area, situated in Belo Horizonte, that present socioeconomic and urban contrasts. Starting from the notion of geography of opportunities, we compared the strategies used and school choices made by families that lived in these two areas, aiming to identify how the socio-economic characteristics of the environment constrained or favored their schooling preferences. The results indicated an effect of the unequal distribution of school opportunities on the parental choices, derived from the quantitative and qualitative characteristics of local school offer.

KEYWORDS: Socio-spatial inequalities; Schooling inequalities; School choice.

\section{Introdução}

A segregação residencial opera como um forte mecanismo de reprodução das desigualdades sociais nas grandes metrópoles. Os custos de moradia costumam estar associados à quantidade de recursos e equipamentos (públicos e privados) disponíveis no entorno, e à qualidade da infraestrutura local. Eles também podem estar atrelados a redes de relações sociais que podem facilitar o acesso a oportunidades profissionais e educacionais (ORFIELD \& GÁNDARA, 2009). Assumindo-se que a educação constitui uma das formas centrais de reprodução das desigualdades sociais (BOURDIEU, 1998), o local de moradia pode funcionar, nas grandes cidades, como um mediador crucial dos processos que produzem a desigualdade escolar.

É partindo dessa hipótese que se observou nos últimos anos, no campo da sociologia da educação, a emergência de uma problemática de pesquisa baseada na relação entre as questões urbanas e as questões escolares, em que se tem procurado investigar se e de que maneira a organização social do espaço pode ser tomada como um recurso, tal como os recursos econômicos, culturais e sociais das famílias, contribuindo assim para a reprodução dos processos de desigualdade educacional.

Van Zanten (2005), ao discorrer sobre as transformações sociais ocorridas nas últimas décadas responsáveis pela produção de novos modos de reprodução das desigualdades escolares, cita, entre elas, justamente os processos de segregação espacial nas grandes cidades como uma nova dimensão que poderia promover ou restringir as oportunidades escolares disponíveis às diferentes classes sociais. Os efeitos desses processos poderiam ser percebidos, por exemplo, na distribuição desigual dos equipa- 
mentos educacionais no espaço urbano, bem como na segmentação social que resulta em diferentes lógicas de socialização da juventude.

Ao tratar da inserção da temática urbana nas pesquisas em educação, Ben Ayed (2012) encara essa nova problemática como um dos eixos de renovação do próprio campo da sociologia da educação. Em linha com esse argumento, Ribeiro e Koslinski (2010) consideram tal temática como uma terceira tradição de estudos da área - tendo uma primeira tradição se dedicado a investigar os efeitos das desigualdades familiares sobre a escolarização, e a segunda a estudar o efeito dos programas, currículos e dinâmicas da escola sobre a aprendizagem dos alunos (os chamados estudos sobre o "efeito-escola"). Nesse sentido "(...) se antes os estudos desenvolvidos no campo da sociologia da educação tratavam somente do efeito da família e da escola, agora a vizinhança ou o bairro passam a ser vistos como instâncias também capazes de gerar desigualdades escolares"(RIBEIRO \& KOSLINSKI, p. 15, 2010).

De forma geral, essa nova abordagem sociológica da educação tem procurado investigar o papel e o impacto de determinadas características sociais do entorno sobre a vida escolar dos estudantes e, mais amplamente, os efeitos dos processos de segregação socioespacial sobre a socialização dos jovens e sobre a acentuação da desigualdade da distribuição espacial de equipamentos públicos, como a própria escola. Os possíveis efeitos do entorno poderiam ser observados tanto do ângulo dos alunos, sendo a vizinhança uma instância socializadora, como do ponto de vista das escolas, no que tange à distribuição desigual das oportunidades de acesso a estabelecimentos de ensino de maior ou menor qualidade e, portanto, de acesso ao próprio conhecimento.

O presente artigo tem por base uma pesquisa que se insere nessa nova perspectiva de análise que se interroga sobre "se" e "em que condições" o lugar de moradia pode resultar em vantagem ou desvantagem escolar? Dito em outros termos, o local de residência da família pode se constituir em obstáculo (material e/ou simbólico) à escolarização dos filhos ou, inversamente, pode resultar em benefícios a ela? Existe alguma influência específica da configuração socioespacial do domicilio sobre as escolhas escolares das famílias?

Partindo da noção de "geografia de oportunidades", realizamos uma pesquisa na cidade de Belo Horizonte, tomando como unidade de análise a Regional Barreiro $^{1}$, especialmente duas de suas sub-regiões: o Barreiro de Baixo e o Barreiro de Cima que, apesar de geograficamente contíguas, apresentam diferenças quanto à composição socioeconômica de sua população e quanto aos indicadores de oportunidades educacionais.

Este artigo está estruturado em três seções. Na primeira seção, abordamos as principais pesquisas brasileiras que articularam variáveis urbanas e educacionais, enfatizando o quadro conceitual utilizado no tratamento dessa temática. $\mathrm{Na}$ segunda seção, examinamos as características sociais da região do Barreiro, explorando indicadores socioeconômicos de sua população, bem como a distribuição da oferta escolar existente na região. Por fim, analisamos o modo pelo qual as desigualdades socioeconômicas e escolares, constatadas na região estudada, estruturam as decisões e as estratégias escolares das famílias residentes. 


\section{Desigualdade urbana e desigualdade escolar}

Apesar do histórico interesse da sociologia pelos efeitos da organização do espaço urbano sobre as desigualdades sociais, apenas nos últimos anos o campo da sociologia da educação buscou articular algumas de suas problemáticas tradicionais com a sociologia urbana (KOSLINSKI \& ALVES, 2012; OBERTI, 2005; RIBEIRO \& KOSLINSKI, 2009). O caráter recente dessa abordagem se expressa nas incertezas científicas ainda existentes quanto à natureza e peso dos efeitos derivados do território - seja no plano individual (as ações dos indivíduos), seja no plano estrutural (índices de violência, oferta escolar etc.) - sobre a escolarização. De todo modo, pesquisas nacionais têm se debruçado sobre o tema a partir de diferentes conceitos, procurando verificar se e como as características sociais do espaço urbano podem desempenhar um papel importante nas trajetórias escolares.

Situando-se em uma perspectiva mais ampla da relação entre desigualdade urbana e desigualdade escolar, Ribeiro e Koslinski (2009) analisaram o impacto do que denominam como "efeito metrópole" sobre os resultados escolares. Comparando a média do Índice de Desenvolvimento da Educação Básica (IDEB) dos municípios integrados ou não integrados a regiões metropolitanas, os autores constataram que além da menor cobertura de atendimento à pré-escola, as cidades metropolitanas se caracterizam por um desempenho inferior no IDEB, quando comparadas com os municípios não integrados às grandes metrópoles. Apesar de concentrarem grande parte da riqueza dos estados, as metrópoles brasileiras seriam marcadas por sua incapacidade de oferecer um nível adequado de acesso às oportunidades escolares. Parte da explicação estaria no fato de que, sobre as metrópoles brasileiras, recairiam de maneira mais pronunciada as consequências de uma crise do padrão de sociabilidade que se manifestaria na fragilização dos laços estabelecidos no mercado de trabalho.

Alves, Franco e Ribeiro (2008) empreenderam uma análise da relação entre o padrão de segregação residencial da cidade do Rio de Janeiro e o risco de defasagem escolar de alunos da $4^{\mathrm{a}}$ e $8^{\mathrm{a}}$ série do Ensino Fundamental à luz da noção de "efeito de vizinhança”. A partir de dados do Censo Demográfico de 2000, utilizando modelos estatísticos que controlavam o peso das variáveis socioeconômicas das famílias, os autores constataram a existência de um efeito de lugar sobre os resultados escolares. $\mathrm{O}$ estudo verificou uma associação entre a residência em favelas e o risco de defasagem escolar, associação essa que se fortalece quando a favela se situa nas proximidades de bairros nobres da cidade. A hipótese dos autores é a de que a segregação social e residencial entre "favela e asfalto" mais marcada nesses contextos, está na origem desse fenômeno.

Érnica e Batista (2011), em pesquisa orientada pelo Centro de Estudos e Pesquisas em Educação, Cultura e Ação Comunitária (CENPEC) investigaram o impacto de variáveis urbanas na qualidade das escolas situadas na subprefeitura de São Miguel Paulista, na cidade de São Paulo. Utilizando o conceito de "efeito-território", verificaram que as escolas públicas localizadas em áreas de alta vulnerabilidade social tendiam a obter desempenho inferior (medido pelo IDEB) àquelas situadas em regiões menos vulneráveis, indicando que essa variável poderia de fato limitar as 
oportunidades educacionais oferecidas pelas escolas situadas nessas regiões. Os autores identificaram que os resultados dos alunos na Prova Brasil variavam de acordo com a localização do estabelecimento onde estudavam. Alunos que detinham maiores recursos culturais familiares obtinham menor desempenho quando estudavam em escolas situadas em vizinhanças socialmente mais vulneráveis, ao passo que, inversamente, alunos de famílias com menos recursos culturais alcançavam desempenhos superiores em estabelecimentos escolares de áreas menos vulneráveis, o que indica que a organização social do território exerce algum impacto sobre os níveis de aprendizagem dos alunos.

Particularmente importante para os propósitos desse trabalho, a pesquisa de Zuccarelli e Cid (2010), focalizou a influência das redes sociais da vizinhança na escolha do estabelecimento de ensino pelas famílias, tendo como referência a noção de "geografia de oportunidades". Tal noção, inspirada no trabalho de Galster e Killen (1995), propõe que a análise das escolhas dos indivíduos em contexto urbano, leve em consideração a existência de variações objetivas na distribuição das oportunidades sociais no espaço urbano (geografia objetiva de oportunidades), e as variações subjetivas relativas aos modos como os indivíduos percebem essas oportunidades (geografia subjetiva de oportunidades). Desse modo, ao entrevistar famílias de uma comunidade pobre do Rio de Janeiro, os autores buscaram apreender as razões que levavam alguns pais a optar por escolas locais, enquanto outros direcionavam seus filhos para uma escola pública mais distante do domicílio, localizada em um condomínio fechado de uma região nobre da capital. Segundo os autores, a explicação residiria na diversidade dos vínculos sociais que essas famílias estabelecem com a vizinhança. Enquanto os pais do primeiro grupo se caracterizam por uma relação mais próxima e mais forte com seus vizinhos, os responsáveis que se mobilizaram para conseguir vaga na escola mais distante, exibem laços mais frágeis com sua vizinhança, adotando assim uma estratégia que os autores denominam como "fuga de lugar", para garantir à prole uma oportunidade escolar que consideram superior. A partir daí, a rede de relações sociais constitui um recurso fundamental para a concretização dessa última estratégia, pois os contatos com vizinhos que têm filhos na mesma escola ou com os próprios funcionários do estabelecimento de ensino facilitaram a obtenção de vagas.

\section{Desigualdade socioespacial e de oportunidades educacio- nais no barreiro}

Entendendo o território como "um espaço apropriado e transformado pela atividade humana” (ÉRNICA \& BATISTA, 2011, p. 25), constituído não apenas pela dimensão físico-espacial, mas também pelas relações socioeconômicas que nele se desenvolvem, partimos da noção de "geografia de oportunidades" para verificar se e como as escolhas das escolas pelas famílias pesquisadas são influenciadas por características sociais do espaço em que vivem. Nesta seção, abordaremos principalmente os elementos da "geografia objetiva de oportunidades" que configuram as duas sub-regiões analisadas.

Com o objetivo de comparar estratégias e escolhas parentais em diferentes contextos socioespaciais, selecionamos a Regional Barreiro como território de pesqui- 
sa por atender aos seguintes critérios: (i) ser uma área com relativa diversidade social, definida a partir da renda dos habitantes; (ii) possuir uma densa oferta escolar no nível do Ensino Básico. Combinados, esses dois critérios possibilitariam investigar as possíveis influências da desigualdade socioespacial sobre as escolhas escolares das famílias.

A partir daí, utilizamos a unidade espacial “área de ponderação", construída pelo Instituto Brasileiro de Geografia e Estatística (IBGE), para definir as sub-regiões onde selecionamos as famílias a serem entrevistadas: Barreiro de Baixo e Barreiro de Cima. As figuras abaixo exibem a localização do Barreiro², na cidade de Belo Horizonte, e suas áreas de ponderação, destacando-se as sub-regiões focalizadas neste trabalho.

Figuras 1 e 2 - Localização da Regional Barreiro e Áreas de Ponderação do Barreiro
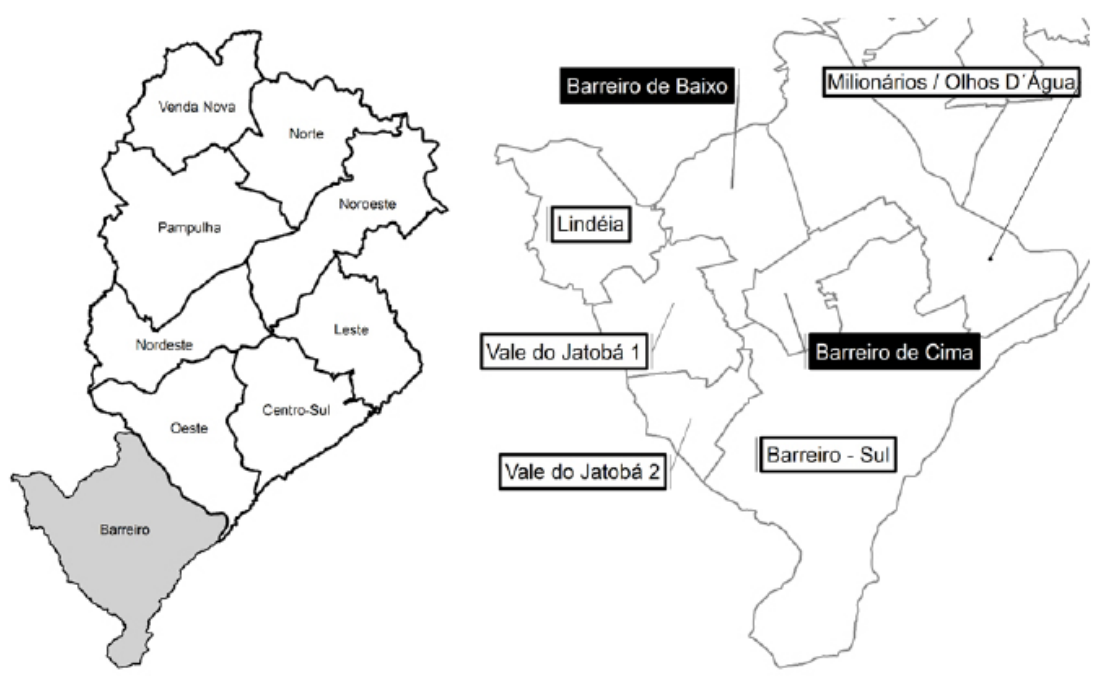

Fonte: Elaboração dos autores a partir de dados da Prefeitura de Belo Horizonte

O Barreiro pode ser caracterizado como uma região de "camada popular heterogênea" (KAZTMAN, 2001), que apresenta uma composição diversificada com forte predominância de segmentos das camadas populares, mas também com presença de ocupações típicas dos segmentos médios. No entanto, essas ocupações estão distribuídas de maneira desuniforme no território da Regional Barreiro. Historicamente, a sub-região do Barreiro de Baixo definiu-se como ponto central dos serviços e comércios da região, abrigando a maior parte dos segmentos médios da população. O Barreiro de Cima posiciona-se como uma área intermediária da região, tanto pelo menor desenvolvimento dos serviços, como em relação ao nível socioeconômico menos elevado de seus residentes.

Essa situação pode ser ilustrada pela Tabela 1, que apresenta a distribuição de cada grupo ocupacional da População Economicamente Ativa (de pessoas acima de 10 anos de idade) nas áreas de ponderação do Barreiro. Nela, é possível identificar a 
configuração diferenciada e segmentada da região. O Barreiro de Baixo apresenta uma proporção maior de residentes em categorias ocupacionais mais elevadas. O Barreiro de Cima, por sua vez, encontra-se em uma posição socioeconômica intermediária quando comparado com as demais áreas de ponderação.

Tabela 1 - Distribuição espacial das ocupações no Barreiro

\begin{tabular}{|c|c|c|c|c|c|c|c|}
\hline & Milionários & $\begin{array}{l}\text { Barreiro } \\
\text { de Baixo }\end{array}$ & $\begin{array}{l}\text { Barreiro } \\
\text { de Cima }\end{array}$ & $\begin{array}{l}\text { Barreiro } \\
\text { - Sul }\end{array}$ & Lindéia & $\begin{array}{l}\text { Vale do } \\
\text { Jatobá } 1\end{array}$ & $\begin{array}{l}\text { Vale do } \\
\text { Jatobá } 2\end{array}$ \\
\hline Diretores e gerentes & 3.52 & 5.96 & 3.80 & 2.96 & 2.90 & 2.74 & 0.98 \\
\hline $\begin{array}{c}\text { Profissionais das ciências e } \\
\text { intelectuais }\end{array}$ & 5.59 & 14.45 & 8.65 & 8.15 & 8.82 & 3.61 & 4.54 \\
\hline $\begin{array}{c}\text { Técnicos e profissionais de } \\
\text { nível médio }\end{array}$ & 9.43 & 10.81 & 9.92 & 6.92 & 8.46 & 6.40 & 5.53 \\
\hline $\begin{array}{l}\text { Trabalhadores de apoio } \\
\text { administrativo }\end{array}$ & 11.51 & 11.89 & 13.42 & 10.79 & 9.80 & 10.87 & 11.54 \\
\hline $\begin{array}{c}\text { Trabalhadores dos serviços, } \\
\text { vendedores dos comércios } \\
\text { e mercados }\end{array}$ & 22.86 & 21.33 & 24.06 & 21.29 & 17.90 & 23.11 & 18.94 \\
\hline $\begin{array}{c}\text { Trabalhadores qualificados } \\
\text { da agropecuária, florestais, } \\
\text { da caça e da pesca }\end{array}$ & 0.29 & 0.43 & 0.08 & 0.92 & 0.36 & 0.09 & 0.16 \\
\hline $\begin{array}{l}\text { Trabalhadores qualificados, } \\
\text { operários e artesãos da } \\
\text { construção, das artes } \\
\text { mecânicas e outros ofícios }\end{array}$ & 15.32 & 10.86 & 11.59 & 13.73 & 16.79 & 14.92 & 16.83 \\
\hline $\begin{array}{l}\text { Operadores de instalações } \\
\text { e máquinas e montadores }\end{array}$ & 8.91 & 9.95 & 11.03 & 12.01 & 13.59 & 11.90 & 12.56 \\
\hline Ocupações elementares & 18.30 & 8.76 & 12.13 & 18.51 & 15.33 & 21.10 & 23.96 \\
\hline $\begin{array}{l}\text { Membros das forças } \\
\text { armadas, policiais e } \\
\text { bombeiros militares }\end{array}$ & 0.14 & 0.54 & 0.59 & 0.44 & 0.17 & 0.34 & - \\
\hline Ocupações mal definidas & 4.13 & 5.03 & 4.74 & 4.27 & 5.88 & 4.91 & 4.96 \\
\hline
\end{tabular}

Fonte: Elaboração dos autores a partir de dados do IBGE 
Essa distribuição desigual dos grupos ocupacionais no território do Barreiro está associada a uma geografia desigual das oportunidades educacionais como exposto na Tabela 2 abaixo. Nela, exibimos o número de instituições escolares disponíveis (por rede de ensino) nas sub-regiões do Barreiro de Baixo e Barreiro de Cima, acompanhado do Nível Socioeconômico Médio (NSE) ${ }^{3}$ do alunado e, no caso das escolas públicas, do Índice de Desenvolvimento da Educação Básica (IDEB) médio para o ano de 2013.

Tabela 2 - Distribuição e caracterização da oferta educacional do Barreiro de Baixo e Barreiro de Cima ${ }^{4}$

\begin{tabular}{|c|c|c|c|c|c|c|c|}
\hline & & \multicolumn{4}{|c|}{ Rede Pública } & \multicolumn{2}{|c|}{ Rede Privada } \\
\hline & $\begin{array}{c}\text { Número de } \\
\text { estabelecimentos de } \\
\text { Ensino } \\
\text { Fundamental } \\
\end{array}$ & $\begin{array}{c}\text { Número de } \\
\text { estabelecimentos } \\
\text { de Ensino Médio }\end{array}$ & $\begin{array}{l}\text { IDEB } \\
\text { Médio } \\
\text { Anos } \\
\text { Iniciais }\end{array}$ & $\begin{array}{l}\text { IDEB } \\
\text { Médio } \\
\text { Anos } \\
\text { Finais } \\
\end{array}$ & $\begin{array}{l}\text { NSE } \\
\text { Médio }\end{array}$ & $\begin{array}{c}\text { Número de } \\
\text { estabelecimentos de } \\
\text { Ensino } \\
\text { Fundamental } \\
\end{array}$ & $\begin{array}{c}\text { Número de } \\
\text { estabelecimentos } \\
\text { de Ensino Médio }\end{array}$ \\
\hline $\begin{array}{c}\text { Barreiro } \\
\text { de Baixo }\end{array}$ & 8 & 4 & 6.8 & 4.8 & 5.7 & 12 & 4 \\
\hline $\begin{array}{r}\text { Barreiro } \\
\text { de Cima }\end{array}$ & 8 & 2 & 6.2 & 4.5 & 5.3 & 6 & 2 \\
\hline
\end{tabular}

Fonte: Elaboração dos autores a partir de dados do INEP/MEC e GAME/FAE/UFMG

Como se vê, a oferta escolar se encontra desigualmente distribuída entre as duas sub-regiões. Essa desigualdade incide tanto sobre o aspecto quantitativo (quantidade de escolas públicas e privadas), como qualitativo (IDEB). Acrescente-se que essa geografia desigual de oportunidades educacionais está associada ainda a uma segmentação socioeconômica do alunado dos estabelecimentos de ensino das duas áreas (NSE médio das escolas públicas).

\section{Escolha da escola em um contexto de oportunidades educacionais desiguais}

A análise da configuração socioespacial do Barreiro demonstra que a região apresenta uma dinâmica de desigualdade socioespacial em que a distribuição desigual das oportunidades educacionais está associada a uma segmentação socioespacial da população. Mas de que modo esse contexto condiciona as estratégias educativas das famílias, considerando sua posição social (renda, ocupação e escolaridade) e espacial (localização da residência)? Em particular, nosso interesse reside na maneira como a distribuição desigual de oportunidades educacionais no Barreiro impacta a geografia subjetiva de oportunidades das duas sub-regiões.

Com esse objetivo, entrevistamos, a partir de roteiros semiestruturados, 17 progenitores cujos(as) filhos(as) cursavam a Educação Básica - sendo 10 famílias residentes no Barreiro de Baixo e 7 famílias residentes no Barreiro de Cima. ${ }^{5}$ A seleção dos entrevistados ocorreu principalmente por meio de contatos fornecidos por associações de moradores e estabelecimentos de ensino da região, mas também por conhecidos que viviam no Barreiro. Para compreender melhor a realidade da oferta educacional local, entrevistamos ainda 4 trabalhadores em educação de quatro esta- 
belecimentos de ensino (duas diretoras, um vice-diretor e um supervisor) - dois deles situados no Barreiro de Baixo e dois no Barreiro de Cima.

\section{Barreiro de Baixo}

Apesar de constituir uma área de ponderação com características socioeconômicas que diferem da sub-região do Barreiro de Cima, existem, no Barreiro de Baixo, variações internas referentes a aspectos urbanos e sociais que não poderiam ser apreendidos adequadamente se tomássemos essa unidade espacial como sendo homogênea. Para lidar com essas diferenças socioespaciais, dividimos a análise das escolhas das famílias residentes do Barreiro de Baixo em dois subgrupos de acordo com o local em que viviam: "centro" e "área pericentral". ${ }^{6}$

O primeiro subgrupo é composto por 4 famílias e o segundo por 6 - totalizando 10 genitores entrevistados (pais ou mães) que vivem nessa sub-região. Como se verá adiante, a essas subdivisões espaciais correspondem diferenças socioeconômicas e de preferências escolares das famílias entrevistadas.

\section{Famílias da área central do Barreiro de Baixo}

A área central Barreiro de Baixo concentra a maior parte dos serviços, comércio e locais de sociabilidade de todo o Barreiro, funcionando como centro econômico, político e social da regional. Os pais que vivem nessa área estão inseridos em um contexto escolar mais amplo e variado, composto por uma oferta maior e diversificada de escolas públicas e privadas. $\mathrm{O}$ quadro abaixo reúne algumas das principais características das quatro famílias entrevistadas que vivem na parte central do Barreiro de Baixo.

Quadro 1 - Famílias entrevistadas da área central do Barreiro de Baixo

\begin{tabular}{|c|c|c|c|c|c|}
\hline \multirow{2}{*}{ Família } & \multicolumn{2}{|c|}{ Máe } & \multicolumn{2}{c|}{ Pai } & Território \\
\cline { 2 - 6 } & Profissão & Escolaridade & Profissão & Escolaridade & $\begin{array}{c}\text { Rendimento médio em } \\
\text { Salário Mínimo do Setor } \\
\text { Censitário }\end{array}$ \\
\hline 1 & $\begin{array}{c}\text { Professora de } \\
\text { educaçáo } \\
\text { básica }\end{array}$ & $\begin{array}{c}\text { Superior } \\
\text { completo }\end{array}$ & $\begin{array}{c}\text { Engenheiro } \\
\text { industrial }\end{array}$ & $\begin{array}{c}\text { Superior } \\
\text { completo }\end{array}$ & 5.59 \\
\hline 2 & Manicure & $\begin{array}{c}\text { Médio } \\
\text { completo }\end{array}$ & $\begin{array}{c}\text { Técnico de rede } \\
\text { e computação }\end{array}$ & $\begin{array}{c}\text { Médio } \\
\text { completo }\end{array}$ & 5.59 \\
\hline 3 & $\begin{array}{c}\text { Professora de } \\
\text { educaçáo } \\
\text { básica }\end{array}$ & $\begin{array}{c}\text { Superior } \\
\text { completo }\end{array}$ & $\begin{array}{c}\text { Professor de } \\
\text { educaçáo básica }\end{array}$ & $\begin{array}{c}\text { Superior } \\
\text { completo }\end{array}$ & 6.9 \\
\hline 4 & Dona de casa & $\begin{array}{c}\text { Médio } \\
\text { incompleto }\end{array}$ & Advogado & Pós-graduação & 5.69 \\
\hline
\end{tabular}

Fonte: Elaboração própria a partir de dados do IBGE e INEP/MEC 
Os pais entrevistados dessa área têm um nível médio de escolaridade superior aos demais habitantes, acompanhando a tendência sociocultural da população do Barreiro de Baixo. Com exceção da "Família 2", todas as demais contam com pelo menos um progenitor com diploma de ensino superior e exercem ocupações de rendimento e status mais elevado - quando comparadas às famílias da área pericentral do Barreiro de Baixo e às famílias da sub-região do Barreiro de Cima.

Entre todas as quatro famílias desse subgrupo, o processo de escolha da instituição escolar para os filhos ocorreu a partir de um leque restrito de opções viáveis, limitado às escolas particulares mais próximas de seus domicílios. Há aqui uma certa desconsideração das opções e características das escolas públicas existentes na região, pois as preferências escolares estão fundamentalmente voltadas para a rede privada. São pais que cultivam uma percepção muito negativa do ensino público. Consideram, por exemplo, que sua qualidade piorou muito nos últimos anos, especialmente no que se refere à segurança, à disciplina e à influência supostamente negativa da clientela sobre seus filhos.

(...) hoje a gente percebe que não é só questão da qualidade, tem questão da segurança. Você tem até receio de pôr o filho numa escola pública. Pelo convívio... Se ele vai ser mal influenciado e ser levado pra um outro rumo, entendeu? (PAI, FAMÍLIA 1, 2014).

No ato de decisão sobre a escola a ser frequentada pelos filhos, esses pais consideraram principalmente dois colégios privados de grande tradição que funcionam no Barreiro de Baixo. A reputação de que desfrutam na região, repercutida nas opiniões de amigos e pessoas conhecidas que vivem no Barreiro, está entre as principais razões apontadas pelos pais para justificar sua preferência. Ainda assim, o prestígio dessas escolas foi complementado por visitas aos colégios para conhecer melhor o espaço e o corpo de educadores - demonstrando um grau mais elevado de exigências escolares.

O processo de escolha evidenciado pela "Família 4" exemplifica bem como a combinação entre aspirações escolares mais elevadas e condições socioeconômicas mais favoráveis, orienta as escolhas desse subgrupo. Essa família havia se mudado recentemente para o Barreiro, tendo apenas um filho de 6 anos de idade, que cursava o primeiro ano do ensino fundamental. Segundo a mãe, ela e o marido estavam descontentes com a oferta escolar disponível no município vizinho de Betim, onde viviam anteriormente. Por essa razão, decidiram matricular o filho na região do Barreiro de Baixo, após tomarem conhecimento da existência dos dois colégios acima mencionados. Após visitá-los, a mãe decidiu matricular o filho em um desses estabelecimentos, onde ele iniciou a educação infantil. Posteriormente, o casal deu mais um passo e resolveu alugar um apartamento no Barreiro de Baixo para que pudessem estar mais próximos da escola do filho. Portanto, a escolha desses pais envolve uma mobilização que impulsionou uma transição territorial em busca de melhores oportunidades escolares para o filho único.

O modo como os pais da "Família 2" escolheram a escola de seus dois filhos se diferencia dos casos anteriores, estando ajustado às suas condições de vida mais 
restritas. À época da pesquisa, o casal tinha três filhos: o mais novo com apenas poucos meses de idade, enquanto os dois primogênitos (gêmeos) tinham 6 anos. De modo dferente das outras três famílias, a decisão tomada por esses pais esteve mais vinculada à vantagem ocasional oferecida pelo emprego do marido. Eles matricularam seus dois filhos gêmeos em um colégio privado de pequeno porte, mas muito próximo da residência. O principal motivador da ação foi o fato do pai trabalhar como técnico de informática nesse estabelecimento, o que lhe assegurava um desconto considerável na matrícula. Diferentemente das famílias que se pautaram por aspectos como reputação, clima escolar, nível de exigência etc., a escolha aqui se deveu a uma conveniência de ordem prática. Segundo a mãe, a família dificilmente seria capaz de custear a dupla mensalidade nessa escola, caso não contasse com esse abatimento. Sem isso, provavelmente teriam encaminhado os dois filhos para alguma escola pública do Barreiro de Baixo. Neste caso, em particular, percebe-se que a proximidade geográfica entre o domicílio e a escola resulta em uma dupla oportunidade: o emprego do marido e a escolarização dos filhos em um estabelecimento que consideram ser superior às escolas públicas.

\section{Famílias da área pericentral do Barreiro de Baixo}

O quadro abaixo expõe aos dados das seis famílias que vivem na área aqui denominada "pericentral" do Barreiro de Baixo.

Quadro 2 - Famílias entrevistadas da área pericentral do Barreiro de Baixo

\begin{tabular}{|c|c|c|c|c|c|}
\hline \multirow{2}{*}{ Família } & \multicolumn{2}{|c|}{ Máe } & \multicolumn{2}{c|}{ Pai } & Território \\
\cline { 2 - 6 } & Profissáo & Escolaridade & Profissáo & $\begin{array}{c}\text { Rendimento } \\
\text { médio em } \\
\text { Salário } \\
\text { Mínimo do } \\
\text { Setor } \\
\text { Censitário }\end{array}$ \\
\hline $\mathbf{5}$ & Professora/Desempregada & $\begin{array}{c}\text { Superior } \\
\text { completo }\end{array}$ & Ferroviário & $\begin{array}{c}\text { Médio } \\
\text { completo }\end{array}$ & 6.86 \\
\hline $\mathbf{6}$ & Dona de casa & $\begin{array}{c}\text { Médio } \\
\text { completo }\end{array}$ & $\begin{array}{c}\text { Empregado/Empresa } \\
\text { combustível }\end{array}$ & $\begin{array}{c}\text { Médio } \\
\text { completo }\end{array}$ & 5.89 \\
\hline 7 & Dona de casa & $\begin{array}{c}\text { Médio } \\
\text { completo }\end{array}$ & Metalúrgico & $\begin{array}{c}\text { Médio } \\
\text { completo }\end{array}$ & 4.92 \\
\hline $\mathbf{8}$ & Faxineira terceirizada & $\begin{array}{c}\text { Médio } \\
\text { completo }\end{array}$ & $\begin{array}{c}\text { Vendedor de peças } \\
\text { para a indústria }\end{array}$ & $\begin{array}{c}\text { Médio } \\
\text { completo }\end{array}$ & 5.52 \\
\hline $\mathbf{9}$ & Secretária & $\begin{array}{c}\text { Médio } \\
\text { completo }\end{array}$ & Operário/Aposentado & $\begin{array}{c}\text { Superior } \\
\text { incompleto }\end{array}$ & 4.98 \\
\hline 10 & Dona de casa & $\begin{array}{c}\text { Médio } \\
\text { completo }\end{array}$ & Operário & $\begin{array}{c}\text { Médio } \\
\text { completo }\end{array}$ & 5.52 \\
\hline
\end{tabular}

Fonte: Elaboração própria a partir de dados do IBGE e INEP/MEC 
Como se vê, a diferença em relação ao grupo anterior é importante, pois, apesar de ambos os grupos residirem na mesma área de ponderação, as características socioeconômicas dessas famílias contrastam com aquelas das famílias da área central do Barreiro de Baixo. Somente uma família conta com um progenitor munido de diploma de ensino superior, e a maioria desses pais exercem ocupações de menor status e rendimento.

Diferentemente do grupo anterior, o que marca as escolhas escolares desses pais é a maior distância entre o desejado e o possível. Enquanto as condições de vida das famílias que vivem no centro do Barreiro de Baixo permitem que suas decisões escolares sejam tomadas com maior grau de certeza, os pais deste grupo que matricularam seus filhos em colégios particulares têm de lidar com grandes incertezas quanto à possibilidade de mantê-los nesses estabelecimentos, devido ao sacrifício financeiro imposto ao orçamento familiar. Por essa razão, o tipo de consumo escolar apresentado por essas famílias se aproxima daquele observado por Nogueira (2013), em seu trabalho sobre a opção pela escola privada por parte da "nova classe média" ou "classe C". Devido às condições de existência desse segmento social emergente, o consumo escolar verificado entre essas famílias se caracterizaria por ser "recente" e "instável", diferentemente da classe média tradicional e mais estável, cuja situação econômica e cultural permite que se opte pela escola privada, de modo bem mais sustentável.

Essa situação pode ser ilustrada com o caso da "Família 10" que vive em um pequeno apartamento no interior de um conjunto habitacional destinado a famílias de baixa renda. A filha única do casal, com 12 anos de idade, cursava o ensino fundamental. Ela havia iniciado a educação infantil em um pequeno colégio privado da vizinhança, em razão da preferência dos pais pela rede privada. Contudo, diante de dificuldades financeiras, os pais decidiram transferi-la para a rede pública. Naquele momento, o "cadastro escolar" ${ }^{8}$ designou uma escola pública do Barreiro de Baixo, onde a menina permaneceu por apenas um ano, quando os pais decidiram que ela retornaria para o colégio privado, em função da percepção de uma queda em seu rendimento escolar. Segundo os pais, o fator preponderante para essa decisão se associa às condições pedagógicas da escola pública, cujas turmas consideram superlotadas, prejudicando o trabalho docente.

Quando foi o primeiro ano [do ensino fundamental] a gente foi levar ela pra escola pública, que é uma escola até aqui perto de casa mesmo. Só que aí que a gente observou que o rendimento dela... não era bom, caiu. Aí a gente foi e retornou pra escola particular, onde ela tá até hoje (...). Vi que apesar de ter bons professores, porém é mais questão de estrutura mesmo. Sala muito cheia, o professor não tem aquela disponibilidade pra dar aula pra 40 alunos, 45 alunos. Aí... resolvi tirar. (MÃE, FAMÍLIA 10, 2014).

Para esses pais, a opção pelo ensino privado constitui um sacrifício recompensador, pois consideram a filha muito dedicada e interessada nos estudos:

(...) assim, é uma despesa que eu vou falar pra você que não compromete o nosso orçamento? Compromete. E muito! (...) Porém a gente deixa de investir em algumas coisas (...). Deixa de investir em uma roupa nova, em um tênis bacana, pra comprar os livros (...). A gente leva a educação muito a sério. (MÃE, FAMÍLIA 10, 2014). 
Experiência semelhante foi relatada pela "Família 7" que tem dois filhos, uma menina e um menino de, respectivamente, 11 e 6 anos de idade à época da pesquisa. Ambos iniciaram sua vida escolar na rede pública. Contudo, após os pais tomarem conhecimento de um programa de descontos na matrícula oferecido a industriários por um colégio técnico de pequeno porte instalado na área central do Barreiro de Baixo, decidiram transferir os filhos para esse estabelecimento.

Assim... Até que o ensino [da escola pública] eu gostei. A professora que ela [a filha mais velha] pegou era uma professora muito boa, eu gostei do ensino. Mas a escola muito judiada, muito! Falta tudo na escola. De estrutura falta tudo. (...) Quando chovia às vezes a sala molhava. Parece assim que a escola foi construída (...) e nunca mais voltou lá pra uma reforma, entendeu? (MÃE, FAMÍLIA 7, 2014).

Se essas famílias conseguiram financiar os estudos de seus filhos na rede privada, embora com dificuldades e mediante descontos, o mesmo não ocorreu com as demais que, diante de um orçamento limitado, tiveram de se limitar à oferta de ensino público.

Face a isso, essas últimas puseram em prática a estratégia de interferência na designação estipulada pelo "cadastro escolar" - evitando determinadas instituições de esnsino, em favor de outras mais desejadas. Nesse sentido, contatos com pessoas que trabalham em escolas públicas ou que estão envolvidas com as redes de ensino estadual ou municipal tornam-se recursos importantes. Outra vantagem para a obtenção de vaga no estabelecimento desejado consiste no fato de ter ou ter tido outro filho que frequenta ou frequentou a escola pleiteada. É que, ao que tudo indica, diretores ou supervisores das escolas tendem a dar preferência, na matrícula, para parentes de alunos da escola, objetivando evitar a entrada de estudantes de origem desconhecida.

A "Família 8", por exemplo, adotou tal estratégia e se mobilizou intensamente para conseguir uma vaga na escola pública onde sua filha única, com 8 anos à época da pesquisa, cursava o $3^{\circ}$ ano do ensino fundamental. Originalmente, o desejo dos pais era o de que ela frequentasse algum dos colégios privados mais tradicionais do Barreiro. Porém, face à impossibilidade financeira de realizar tal vontade, eles se movimentaram para conseguir uma vaga no estabelecimento público que consideravam como a melhor opção possível dentro da oferta escolar do Barreiro - uma escola pública, situada no Barreiro de Baixo, que oferece somente o ensino fundamental e que goza de reputação muito positiva na região. O pai conta que, inicialmente, burlou o cadastro escolar mediante o uso do endereço de um conhecido que vivia próximo à escola desejada. Contudo, mesmo após recorrer a esse subterfúgio, a filha foi designada para uma escola pública que foi rejeitada por ele. Inconformada, a família insistiu em pleitear uma vaga nos estabelecimentos mais próximos do centro do Barreiro de Baixo.

Falei “não", pro [nome do estabelecimento] eu não vou! Porque o [nome do estabelecimento] não sei se você conhece, já ouviu falar. Era uma escola no passado, quando estudei lá (...) eram escolas referência. Com o passar dos anos, de primeira a oitava... Acabou! (...) Disse, de jeito maneira! Eu não vou deixar ela lá! Sinceridade. Eu ia pagar escola pra ela, mas lá eu não ia deixar! (PAI, FAMÍLIA $8,2014)$. 
Não contente com essa situação, ele passou a visitar frequentemente a escola que ele e a esposa desejavam, perguntando à diretoria sobre a abertura de vagas. Além disso, recorreu a outro conhecido, funcionário da própria Secretaria de Educação estadual, solicitando que o avisasse por ocasião da abertura de vaga no referido estabelecimento, em tempo hábil para o contato com a direção do estabelecimento - o que acabou ocorrendo alguns meses depois, quando, finalmente pôde matricular a filha.

A estratégia adotada por esse pai remete a práticas que podem ser denominadas como clientelistas ou patrimonialistas, também identificadas no contexto da cidade do Rio de Janeiro, em pesquisa de Costa e Koslinski (2012), dedicada a analisar o fenômeno da competição por vagas em escolas públicas. Segundo esses dois autores, a existência de uma "permeabilidade" do sistema escolar possibilita que algumas famílias estabeleçam contatos com órgãos administrativos das escolas (secretarias, diretorias), objetivando obter vagas por meios oficiosos. De todo modo, diante de uma distribuição desigual das oportunidades educacionais no espaço urbano, essas famílias procuram superar as restrições impostas pelo local onde vivem. Como abordaremos mais adiante, esse tipo de estratégia ganhará ainda mais importância no contexto escolar mais restritivo do Barreiro de Cima.

\section{Barreiro de Cima}

A análise das características sociais da região e da distribuição espacial das oportunidades educacionais demonstra que o Barreiro de Cima se caracteriza por um quadro escolar mais restrito, composto por escolas públicas que vêm apresentando baixo desempenho no IDEB. Nesse contexto, o que se destaca é a adoção de práticas de evitamento escolar por parte de quase todas as famílias entrevistadas que vivem nessa sub-região - com exceção das famílias 16 e 17. Desfavorecidos na distribuição espacial das oportunidades educacionais na região e movidos pela insatisfação com a oferta local, boa parte dos pais entrevistados declarou ter preferência pelas escolas do Barreiro de Baixo, e interferiu, de maneiras variadas, na designação feita pelo cadastramento escolar, a fim de obter uma vaga na escola desejada.

Se o grupo de famílias que vive na área pericentral do Barreiro de Baixo se caracteriza pelo dilema entre seus desejos e a possibilidade de concretizá-los, os pais do Barreiro de Cima estão fadados quase que inexoravelmente ao ensino público. Isso se deve, em grande medida, ao perfil socioeconômico relativamente mais desfavorecido dessas famílias. Além dos aspectos que expressam a posição social dessas famílias, observamos também que suas residências estão situadas em vizinhanças com rendimento médio inferior às do grupo do Barreiro de Baixo, como exposto no quadro abaixo: 
Quadro 3 - Famílias do Barreiro de Cima

\begin{tabular}{|c|c|c|c|c|c|}
\hline \multirow[b]{2}{*}{ Família } & \multicolumn{2}{|c|}{ Máe } & \multicolumn{2}{|c|}{ Pai } & \multirow{2}{*}{$\begin{array}{c}\text { Território } \\
\text { Rendimento médio em } \\
\text { Salário Mínimo do } \\
\text { Setor Censitário }\end{array}$} \\
\hline & Profissão & Escolaridade & Profissão & Escolaridade & \\
\hline 11 & Secretária & $\begin{array}{c}\text { Médio } \\
\text { completo }\end{array}$ & Porteiro & $\begin{array}{c}\text { Médio } \\
\text { completo }\end{array}$ & 3.66 \\
\hline 12 & $\begin{array}{l}\text { Vendedora } \\
\text { autônoma }\end{array}$ & $\begin{array}{c}\text { Médio } \\
\text { incompleto }\end{array}$ & Marceneiro & $\begin{array}{c}\text { Médio } \\
\text { incompleto }\end{array}$ & 3.88 \\
\hline 13 & Manicure & $\begin{array}{l}\text { Fundamental } \\
\text { incompleto }\end{array}$ & $\begin{array}{l}\text { Dono de } \\
\text { restaurante }\end{array}$ & $\begin{array}{l}\text { Médio } \\
\text { incompleto }\end{array}$ & 4.52 \\
\hline 14 & Balconista de loja & $\begin{array}{l}\text { Médio } \\
\text { completo }\end{array}$ & Pedreiro & $\begin{array}{c}\text { Médio } \\
\text { completo }\end{array}$ & 4.96 \\
\hline 15 & $\begin{array}{c}\text { Professora de } \\
\text { educaçáo básica/ } \\
\text { Aposentada }\end{array}$ & $\begin{array}{l}\text { Superior } \\
\text { completo }\end{array}$ & $\begin{array}{l}\text { Assessor da } \\
\text { assembleia }\end{array}$ & $\begin{array}{l}\text { Superior } \\
\text { completo }\end{array}$ & 3.28 \\
\hline 16 & $\begin{array}{l}\text { Comerciante } \\
\text { autônoma }\end{array}$ & $\begin{array}{c}\text { Médio } \\
\text { incompleto }\end{array}$ & $\begin{array}{l}\text { Professor de } \\
\text { línguas }\end{array}$ & $\begin{array}{c}\text { Superior } \\
\text { incompleto }\end{array}$ & 4.67 \\
\hline 17 & $\begin{array}{c}\text { Operadora } \\
\text { telemarketing }\end{array}$ & $\begin{array}{l}\text { Médio } \\
\text { completo }\end{array}$ & $\begin{array}{c}\text { Entregador } \\
\text { autônomo } \\
\text { /Aposentado }\end{array}$ & $\begin{array}{l}\text { Médio } \\
\text { completo }\end{array}$ & 4.48 \\
\hline
\end{tabular}

Fonte: Elaboração própria a partir de dados do IBGE e INEP/MEC.

Diante desse contexto, verificamos que as estratégias e escolhas escolares dessas famílias se dividem em duas orientações: (i) mobilização para obtenção de uma vaga em escolas do Barreiro de Baixo; (ii) aceitação da determinação do cadastro escolar, seja em razão da satisfação da família com a oferta escolar local, seja em função de uma postura de resignação. Como se verá, a definição de cada uma dessas atitudes depende também dos recursos culturais e econômicos possuídos pelas famílias, bem como da percepção que têm das escolas locais.

O primeiro modo de escolha escolar está assentado em uma opinião bastante negativa das escolas públicas do Barreiro de Cima, demonstrando preferência pelos estabelecimentos que funcionam na sub-região vizinha do Barreiro de Baixo. Aqui, uma das principais preocupações expostas pelas famílias se refere à segurança física dos filhos, mas também ao nível de exigência das escolas. A proximidade com vilas e favelas marcadas pela vulnerabilidade social, torna-se um dos elementos que levam as famílias a associar o clima da escola ao clima social do bairro em que ela está situada - principalmente aquelas que vivem mais distantes do Barreiro de Baixo. Por essas razões, práticas de evitamento escolar são verificadas entre esses pais e podem ser compreendidas aqui como estratégias de superação das restrições locais em vista das oportunidades educacionais disponíveis na área onde vivem. 
A "Família 13" oferece um exemplo ilustrativo nesse sentido. O casal tem apenas um filho único, com 16 anos idade, que cursava o $1^{\circ}$ ano do Ensino Médio, tendo passado por uma reprovação no ensino fundamental. Os pais evitaram a escola pública mais próxima da residência, principalmente em razão de informações recebidas sobre o nível de indisciplina e violência ali reinante - situação que a mãe associa à proximidade do estabelecimento com uma favela da região. Mediante o comprovante de endereço cedido por pessoa conhecida, burlaram o cadastramento escolar e matricularam o filho em uma escola pública do Barreiro de Baixo.

Outro fenômeno evidenciado pelo exame das escolhas efetuadas por esse grupo de famílias, diz respeito às exíguas opções de estabelecimentos que atendem o ensino médio disponíveis no Barreiro de Cima. Essa situação - juntamente com a percepção negativa dos pais sobre as escolas públicas de nível médio da região - torna o momento de transição do ensino fundamental para o ensino médio permeado de dúvidas e de incertezas para as famílias.

Essa situação pode ser exemplificada pelo caso da "Família 15" que vive em um dos bairros mais empobrecidos do Barreiro de Cima. A filha mais velha do casal cursava Direito em uma faculdade particular de Belo Horizonte, enquanto a filha mais nova, de 14 anos, frequentava o $9^{\circ}$ ano do ensino fundamental. Apesar de a primogênita ter cursado o ensino médio em um dos colégios privados de maior prestígio do Barreiro de Baixo, o pai afirmou que provavelmente não seria capaz de oferecer a mesma oportunidade à filha caçula, pois a condição financeira da família havia declinado. Assim, estando ela atualmente matriculada em uma escola pública do Barreiro de Cima que oferece somente o ensino fundamental, esse pai se dizia disposto a evitar as escolas locais de ensino médio, como meio de compensar a impossibilidade de matriculá-la em um estabelecimento de ensino privado da região.

Quanto mais a gente vai chegando mais pra lá [apontando para a direção do Barreiro de Baixo], vai melhorando [as escolas]. (...) Então assim, a escola de lá é melhor. Eu vou ter custo, vou ter que pagar passagem [transporte coletivo] pra ela. Ou eu coloco ela no centro, no centro da capital [Belo Horizonte], numa escola pública que é boa ou então põe ela no Barreiro de Baixo que também é uma escola boa, sabe? (PAI, FAMÍLIA 15, 2014).

Por fim, constatou-se entre as demais famílias entrevistadas uma lógica de aceitação da oferta escolar local. Esses pais não deixaram de tecer críticas à qualidade das escolas públicas do Barreiro de Cima, contudo, não evitaram a oferta local e aceitaram a designação feita pelo cadastro escolar. Nesse sentido, não se pode perder de vista que o desenvolvimento de atitudes de evitamento requer a posse de recursos sociais (contatos e conhecidos com trânsito no sistema escolar); culturais (conhecimento mais amplo da oferta educacional); e também econômicos (contratação de um serviço de transporte escolar, custeio de passagens de transporte coletivo etc.). Recursos esses que, em maior ou menor grau, diferenciam essas famílias das anteriores.

O relato oferecido pela mãe da "Família 17" exemplifica essa situação. Essa família tem dois filhos pequenos: um com 10 e outro com 8 anos de idade que cursavam, respectivamente, o $5^{\circ}$ e o $3^{\circ}$ ano do ensino fundamental. Para essa família, a 
ausência de recursos (econômicos e sociais) exigidos para conseguir uma vaga nos estabelecimentos do Barreiro de Baixo, limitou-a à adoção das oportunidades escolares locais. A mãe disse ter cogitado burlar o cadastro, para tentar matricular os filhos em algum estabelecimento do Barreiro de Baixo. Todavia, ela desistiu dessa ideia em razão da distância geográfica, que demandaria a contratação de transporte escolar, bem como por não ter conhecidos a quem solicitar comprovante de endereço para utilizar no momento da matrícula. Apesar de se dizer satisfeita com a escola onde os filhos estudavam, ela aparentou preocupação com o momento da transição das séries iniciais do ensino fundamental para as séries finais, ao tomar conhecimento, por meio de vizinhos, que a escola para onde seus filhos seriam direcionados teria sérios problemas de indisciplina discente.

\section{Considerações finais}

Os resultados desta pesquisa apontam para a influência das características sociais do território sobre as estratégias educativas das famílias, em particular, sobre aquelas associadas à escolha do estabelecimento de ensino para os filhos, sem com isso negar o papel determinante dos recursos econômicos, culturais e sociais de que dispõem os pais. Entretanto, é grande a dificuldade de se dissociar os efeitos específicos do território, das desigualdades sistemáticas relativas a fatores como renda e nível de instrução do núcleo familiar, uma vez que as segmentações socioeconômicas inscritas no espaço urbano tendem - como se sabe - a traduzir as clivagens de classe próprias da estrutura social (BOURDIEU, 2003).

No que tange aos efeitos específicos do território, nossos resultados indicam que a influência da vizinhança sobre as desigualdades de escolarização se associa à disponibilidade e à qualidade da oferta educativa. Com efeito, analisar a distribuição espacial desigual das oportunidades educacionais se mostra significativamente relevante se quisermos compreender como as posições que as famílias ocupam no espaço social e urbano influenciam os percursos escolares de seus filhos.

As famílias que vivem no Barreiro de Baixo contam com um leque de oportunidades educacionais mais amplo e diversificado, mas também (se utilizarmos o IDEB como parâmetro) mais qualificado. Assim, as famílias cujos pais possuem um nível mais elevado de instrução e exercem ocupações mais qualificadas contam com o máximo de recursos possíveis para usufruir de sua posição favorecida na região do Barreiro. Suas escolhas estão direcionadas para os colégios privados mais tradicionais da região. Por outro lado, as famílias que vivem na mesma sub-região, mas não dispõem dos mesmos recursos, tenderam a se dirigir seja para as escolas privadas de menor porte e reputação, seja para as escolas públicas situadas no próprio Barreiro de Baixo.

Contudo, é na situação relativamente desvantajosa em que se encontram as famílias moradoras do Barreiro de Cima que observamos mais claramente a associação entre desigualdades socioespaciais e escolhas escolares. As práticas de evitamento ou de aceitação das escolas do Barreiro de Cima verificadas entre os pais entrevistados funcionam como estratégias de superação das restrições que o local de moradia lhes impõe. Em outras palavras, esses pais procuram reduzir os efeitos que consideram 
potencialmente negativos do território onde vivem, numa atitude semelhante àquela que Zuccarelli e Cid (2010) constataram entre famílias de uma comunidade carente, e que os autores designaram como "fuga de lugar". Determinar se essas decisões terão ressonâncias escolarmente positivas no longo prazo, exigiria um estudo de caráter longitudinal. Considerando, no entanto, que as escolas localizadas no Barreiro de Baixo apresentam indicadores educacionais relativamente superiores, essas estratégias parecem se justificar objetivamente, ao menos, no curto prazo.

\section{Referências}

ALVES, Fátima, FRANCO, Creso, RIBEIRO, Luiz Cesar de Queiroz. "Segregação residencial e desigualdade escolar no Rio de Janeiro." In: RIBEIRO, Luiz César de Queiroz; KAZTMAN, Rubén. A cidade contra a escola. Segregação Urbana e desigualdades educacionais em grandes cidades da América Latina. Rio de Janeiro: Letra Capital/Observatório das Metrópoles, 2008. p. 91-118.

BEN AYED, Choukri. "As desigualdades socioespaciais de acesso aos saberes: uma perspectiva de renovação da sociologia das desigualdades escolares?." Educação \& Sociedade. Tradução Alain François. 33.120.2012.

BOURDIEU, Pierre. A Escola conservadora: as desigualdades frente à escola e à cultura. Tradução Aparecida Joly Gouveia. In: NOGUEIRA, Maria Alice; CATANI, Afrânio (orgs). Escritos de educação. Petrópolis, Vozes, 1998. p. 39-64.

BOURDIEU, Pierre. O efeito de lugar. In: BOURDIEU, Pierre (org.). A miséria do mundo. Tradução Mateus S. Soares Azevedo. Jaime A. Clasen. Sérgio H. de Freitas Guimarães. Marcus Antunes Penchel. Guilherme J. de Freitas Teixeira. Jairo Veloso Vargas. Petrópolis, Vozes, 2003.

COSTA, Márcio. KOSLINSKI, Mariane. Escolha, estratégia e competição por escolas públicas. Pro-Posições, Campinas, v. 23, n. 2, p. 195-213, maio/ago. 2012.

ÉRNICA, Maurício. BATISTA, Antônio G. Educação em territórios de alta vulnerabilidade social na metrópole: um caso na periferia de São Paulo. Informe de Pesquisa. CENPEC, n. 3, Nov. 2011.

GALSTER, George C.; KILLEN, Sean P. The geography of metropolitan opportunity: A reconnaissance and conceptual framework. Housing Policy Debate, v. 6, n. 1, p. 7-43, 1995.

KAZTMAN, Ruben. Seducidos y abandonados: el aislamento social de los pobres urbanos. Revista de la Cepal. N. 75. Dec. 2001.

KOSLINSKI, Mariane C. ALVES, Fátima. Novos olhares para as desigualdades de oportunidades educacionais: a segregação residencial e a relação favela-asfalto no contexto carioca. Educ. Soc., Campinas, v.33, n. 120, p. 805-831, jul.-set. 2012.

NOGUEIRA, Maria Alice. No fio da navalha - A (nova) classe média brasileira e sua opção pela escola particular. In: ROMANELLI, G; NOGUEIRA, M.A.; ZAGO, N. (Org.). Família \& escola - Novas perspectivas de análise. Petropolis: Vozes, v. 1, p. 109-130. 2013.

OBERTI, Marco. Differenciation sociale et scolaire du territoire: inegalites et configurations locales. Sociétés contemporaines, no 59-60, p. 13-42. 2005.

ORFIELD, Gary. GÁNDARA, Patricia. Housing, school segregation and intergenerational inequality in the United States. Policy Brief. 2009. 
RIBEIRO, Luiz Cesar de Queiroz, KOSLINSKI, Mariane. A metropolização da questão social e as desigualdades de oportunidades educacionais no Brasil. In: RIBEIRO, Luiz Cesar de Queiroz. KOSLINSKI, Mariane C. ALVES, Fatima. Desigualdades urbanas, Desigualdades escolares. Rio de Janeiro, Letra Capital/Observatório das Metrólopes/IPPUR/UFRJ. 2010. p. 33-66.

RIBEIRO, Luiz Cesar de Queiroz. KOSLINSKI, Mariane. Efeito metrópole e acesso às oportunidades educacionais. Revista Eure, Vol. XXXV, No 106, pp. 101-129, 2009.

VAN ZANTEN, Agnés. New modes of reproducing social inequality in education: the changing role of parents, teachers, schools and educational policies. European Education Research Journal, Vol. 4, N. 3, 2005.

ZUCCARELLI, Carolina. CID, Gabriel. Oportunidades educacionais e escolhas familiares no Rio de Janeiro. In: RIBEIRO, Luiz Cesar de Queiroz. KOSLINSKI, Mariane C. ALVES, Fatima. Desigualdades urbanas, Desigualdades escolares. Rio de Janeiro, Letra Capital, 2010. p. 249-276.

\section{Notas}

${ }^{1}$ Em termos administrativos, o território político de Belo Horizonte é dividido em nove administrações regionais que funcionam como espécies de subprefeituras.

2 Antes da fundação da capital mineira, em 1897, a região atual do Barreiro era formada por grandes propriedades de terra, destacando-se a Fazenda do Barreiro. Nos primeiros anos, cumpriu uma função de abastecimento alimentício da capital, a partir de pequenas colônias agrícolas. Isso muda na década de 50 com o estabelecimento da siderúrgica Mannesman, atual Valourec, fazendo que a imagem da região seja associada ao lócus do operariado belo-horizontino.

${ }^{3}$ Construído pelos pesquisadores do Grupo de Avaliação e Medidas Educacionais (GAME/FAE/UFMG), em parceria com o Instituto Unibanco, o indicador do NSE sintetiza as características de escolaridade, ocupação e renda das famílias dos alunos de várias escolas, privadas e públicas, do Brasil, obtidas pelos questionários contextuais aplicados pelas avaliações do SAEB.

${ }^{4} \mathrm{O}$ quadro considera a quantidade de opções disponíveis para cada nível de ensino e não necessariamente o número total de escolas. Por exemplo, existem no total 8 estabelecimentos no Barreiro de Baixo: 7 deles que oferecem séries iniciais e/ou finais do Ensino Fundamental, sendo que 4 deles oferecem também o Ensino Médio.

${ }^{5}$ Inicialmente, o objetivo era o de entrevistar 10 famílias de cada área selecionada. No entanto, dificuldades operacionais impossibilitaram atingir o mesmo número de entrevistados para o Barreiro de Cima. Contudo, considerando a diversidade dos contextos socioespaciais representados e das condições de vida das famílias entrevistadas, a quantidade foi satisfatória para os fins da pesquisa.

${ }^{6}$ Apesar das diferenças entre esses dois subgrupos, existe uma homogeneidade no grupo entrevistado que é suficiente para diferenciá-lo do grupo do Barreiro de Cima, onde não foi necessário utilizar esse mesmo procedimento distintivo para análise das famílias entrevistadas.

${ }^{7} \mathrm{O}$ rendimento médio do setor censitário em salários mínimos onde se situava o domicílio da família entrevistada. O setor censitário é uma unidade espacial que agrega aproximadamente 300 residências e compõe as áreas de ponderação do IBGE.

${ }^{8}$ Expressão utilizada, em Belo Horizonte, para designar o procedimento administrativo adotado pelo município, responsável pela distribuição de matrículas de escolas municipais e estaduais. 
* Doutorando em Educação pela Universidade Federal de Minas Gerais, Belo Horizonte, Minas Gerais, Brasil.

** Professora doutora da Universidade Federal de Minas Gerais, Belo Horizonte, Minas Gerais, Brasil.

\section{Correspondência}

Maria Alice de Lima Gomes Nogueira - Universidade Federal de Minas Gerais, Faculdade de Educação, Departamento de Ciências Aplicadas a Educação. Av. Antonio Carlos, 6627, Pampulha. CEP: 31270901. Belo Horizonte, Minas Gerais, Brasil.

E-mail: gustavobrp@gmail.com - malicen@terra.com.br

Recebido em 20 de novembro de 2017

Aprovado em 02 de março de 2018 